\title{
Near infrared colorants with individualized rasters on drug packaging
}

\author{
Vilko Žiljak' ', Denis Jurečić', Jana Žiljak Gršić2 , Ivan Rajković \\ ${ }^{1}$ Faculty of Graphic Arts, University of Zagreb, Croatia \\ ${ }^{2}$ Zagreb University of Applied Science, Zagreb, Croati
}

\begin{abstract}
Safety graphics on drug packaging are presented using infrared colorants according to the recipe for VZ twins for offset printing. The mathematical model of the individual shape of raster (screen) elements, "the FourHorns" (FH), is presented here along with the performance solution in PostScript. Safety procedures have been expanded with linear typography print, but by using low resolution screens on the border of recognition. The design was applied in the print on drug packaging subject to different weather conditions which affect and change the color tone of $\mathrm{V}$ and $\mathrm{Z}$ twins during longer time periods. The visual design $(\mathrm{V})$ is shown and transformed into near infrared spectrum $(Z)$ using the method of digital animation. The presentation is based on the methods of creating animated movies by combining eight photographs which were made using a forensic camera with light filters for the range from 400 to 1000 nanometers. The visual and near infrared absorption of sunlight is shown in continuity, including the Z1 and Z2 area of wavelengths.
\end{abstract}

Keywords: drug packaging, infrared colorants, FourHorn raster (screen), visual and NIR animation, forensic print

\section{Introduction}

At the very beginning of the discovery of InfraredDesign ${ }^{\circ}$, it was pointed out that a new procedure for colorant separation in the print industry had been set, a procedure which combines two independent images [1]. A double image was created for separate viewing in the visual and infrared spectrum. The research into safety graphics and invisible images has been expanded with work in the technical domain and the domain of visual arts [2]. The procedure of "twin colors and colorants", which is used to determine the different compositions of colorants with the same color tone on different materials and in different printing techniques, has been implemented in the InfraredDesign ${ }^{\circ}$ technology. In the journal Applied Mechanics and Materials [4] graphics-oriented authors came forth with suggestions for printing hidden information on documents [5]. More attention is given to the GCR ("Gray Component Replacement) procedure under the title "Security Printing Method by Black Ink Hiding Infrared Image" [6].

IRD has introduced a new vocabulary for communication, defining areas of light as: $\mathrm{V}$ (visual - RGB), Z1 - the transition area (700 to $800 \mathrm{~nm}$ ) that our eye still registers, $\mathrm{Z} 2$ - the area in which NIR graphics are observed, and $\mathrm{Z}$ - the position at $1000 \mathrm{~nm}$. This has produced other new abbreviations in work dealing with IRD and IRA: $Z$ image, $Z$ colorants, $V$ image, $\mathrm{V}$ colorants, $\mathrm{VZ}$ separation, $\mathrm{VZ}$ painting, $\mathrm{VZ}$ color setting [7]. An apparatus calibrated for registering the absorption of light at $1000 \mathrm{~nm}$ $[8,9]$ has been developed. The safety view of IRD and IRA products consists of a series of photographs made with the Projektina forensic system [10]. Registering a series of 24 blockades is the basis for performing the animation of the transition of the image from the visual to the near infrared state at $1000 \mathrm{~nm}$. The spectrography of printing colorants is the basis for the quantitative determining of the domains of their light absorption in the range from 400 to $900 \mathrm{~nm}$. In the development of the 
InfraredDesign ${ }^{\circ}$ technology, the information about the gray twin $\mathrm{S}$ and $\mathrm{Z}$ is significant, which has been published in the journal Polytechnic \& Design [11, 12].

\section{Twins of colors and colorants}

Demonstrated in this paper is the dual design carrying the information on the drug BLENDNIR in the visual spectrum, while the $\mathrm{Z}$ information, nestled in the visual image through the twin colorants method, is manifested in the infrared spectrum (1000 $\mathrm{nm}$ ). The hidden image consists of the word ORIGINAL and the silhouette of a girl drawn with a brush and ink. The complete effect of the design is presented as a video transformation (image 5).

We are planning a pre-press preparation which combines two images for printing with process colorants cyan, magenta, yellow and black. The recipes for twin colorants with iterative adjustments to the quantity of individual process colorants have been experimentally determined. Each pair of colorants (here named "twin colorants") consists of different components (table 1). The twin V consists of C, M, Y colorants, while its twin Z consists of $\mathrm{C}, \mathrm{M}, \mathrm{Y}$ and $\mathrm{K}$ colorants, according to the idea of the GCR procedure of replacing C, M, Y with $\mathrm{K}$. The twins have different compositions, although they are of the same color tone
$\left(L^{*} a^{*} b\right)$ measured after offset printing. Table 1 shows the results of the last experiment when the value DeltaE was less than 4 .

Each line in the word and the silhouette of the portrait has its $\mathrm{X}_{0} / \mathrm{X}_{40}$ twin for colorants which will be used in the BLENDNIR drug design. Table 1 contains the recipes for process colorants: five light twins and five dark twins of colors.

In its distribution path from producer to consumer, drug packaging goes through many different weather conditions. This path very often involves long periods in warehouses, trucks and in-between spaces and short exposures to outside weather conditions during loading. Exposure to these changes negatively affects the mechanical and visual properties of drug packaging, which can result in significant change of the information on its surface. Outside conditions change the tonality of the colors. The effect of the "aging" of colorants is subject to humidity, temperature and light. The twins of colorants $\mathrm{V}$ and $\mathrm{Z}$ were created with different quantities of process colorants which with time change their color tone unequally. Colorant $\mathrm{V}$ does not have carbon black colorants. Colorant $\mathrm{Z}$ has significantly smaller quantities of process colorants C, M, Y (compared to the amount of these colorants in the $\mathrm{V}$ twin colorant). Concerning the weight of the colorants, the $\mathrm{Z}$ twin is roughly twice as easy as the $\mathrm{V}$ twin.

Table 1. Twin colorants

\begin{tabular}{|c|c|c|c|c|c|}
\hline & $\mathrm{V}$ twin & $\mathrm{Z}$ twin & & & \\
\hline & $\mathrm{X}_{0}: \mathrm{C}, \mathrm{M}, \mathrm{Y}, \mathrm{K}=\mathbf{0}(\%)$ & $\begin{array}{l}X_{40}: C_{40}, M_{40}, Y_{40}, \\
K=40\end{array}$ & color & $\mathbf{L}^{\star} \mathbf{a}^{\star} \mathbf{b}$ & $\begin{array}{l}\text { RGB (cca for } \\
\text { orientation) }\end{array}$ \\
\hline 1 & 3640400 & 78640 & & $64,7,10$ & $170,150,140$ \\
\hline 2 & 3140510 & 091740 & & $65,8,20$ & $174,150,120$ \\
\hline 3 & 3137450 & 051040 & & $67,8,45$ & $180,160,130$ \\
\hline 4 & 3032350 & 000040 & & $70,5,10$ & $180,170,150$ \\
\hline 5 & 3836360 & 103140 & & $65,4,6$ & $160,160,150$ \\
\hline 6 & 7478450 & 54481040 & & $29,21,-18$ & $85,60,100$ \\
\hline 7 & 7761720 & 58213440 & & $36,-8,7$ & $80,90,80$ \\
\hline 8 & 8694510 & 44732040 & & $12,30,-20$ & $60,10,60$ \\
\hline 9 & 8252910 & 6255140 & & $39,-20,6$ & $70,100,80$ \\
\hline 10 & 9999380 & 8671040 & & $1,60,-57$ & $30,0,90$ \\
\hline
\end{tabular}




\section{The individual shape of rasters in the separation of colorants according to the $\mathrm{VZ}$ procedure}

It has been experimentally confirmed that the effect of mutual concealment of the $\mathrm{Z}$ and $\mathrm{V}$ images is smaller if their contiguous edges are placed in a continuous straight line. The negative effect of recognizing the $\mathrm{Z}$ image is shown in the hiding of typography with straight edges in letters.

The transition of pairs of colorants from $\mathrm{V}$ to $\mathrm{Z}$ colorants (of the same color) is the key event in our eye. Because of this, we introduce an individual raster (screen) shape with pointed edges in its microstructure. We have created the mathematical form of the raster cell which is complex, but which satisfies the entire area of the coverage of application of graphics in the technology of the simulation of an infinite number of colors. The model of the new raster is called "FourHorns" (image 1). Shapes in image 2 show the mutation which initiates the visual change and individuality even for a small change in coverage.

The mathematical definition of the unitary raster (screen) cell is:

$$
z=\left\|x^{2} / 2-y^{4} / 2\right\|
$$

The program in PostScript which is used to test the brightness of the "FourHorns" (/z) screen is published in this paper:

/z dup mul dup mul 2 div exch dup mul 2 div sub abs\} bind def

/lin 5 def/kut 0 def

lin kut $\{z\}$ bind setscreen

100600 translate 5050 scale

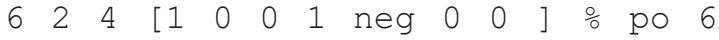

piksla u retku

$\{<$ 8c5b19 a67b4e $>\}$ image
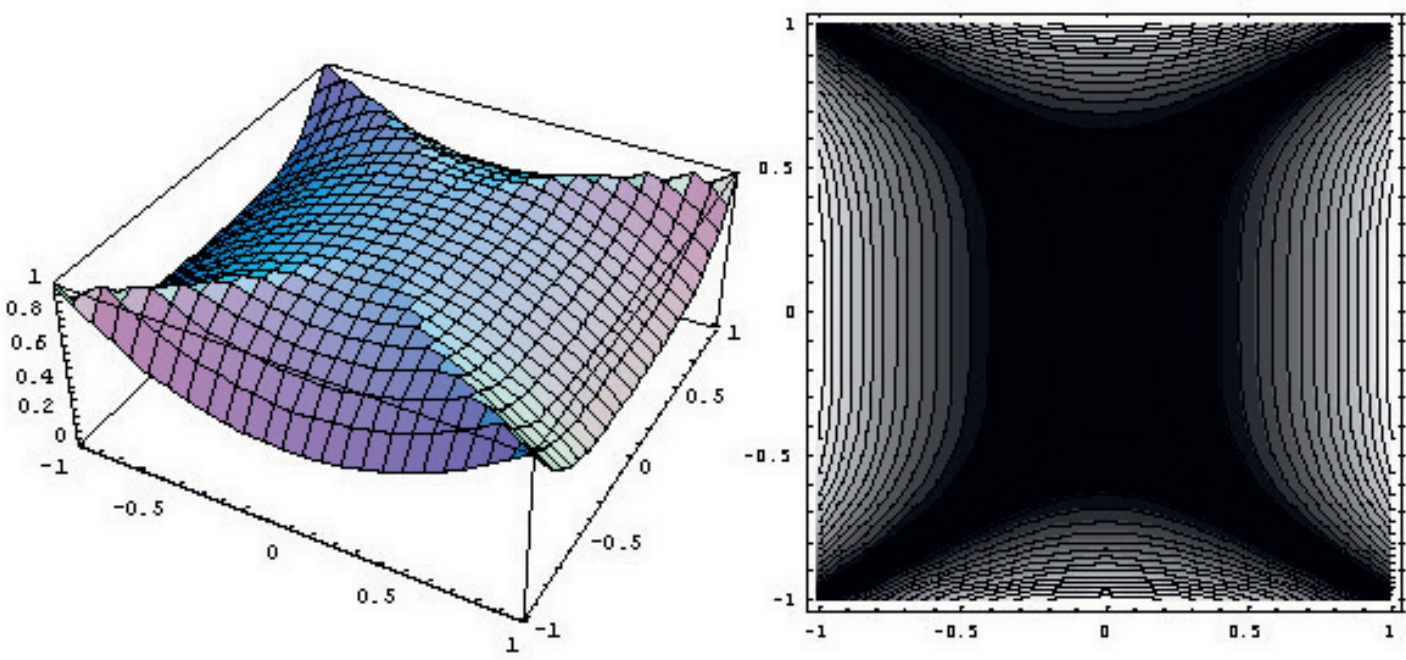

Image 1. "FourHorns" raster (screen) cell

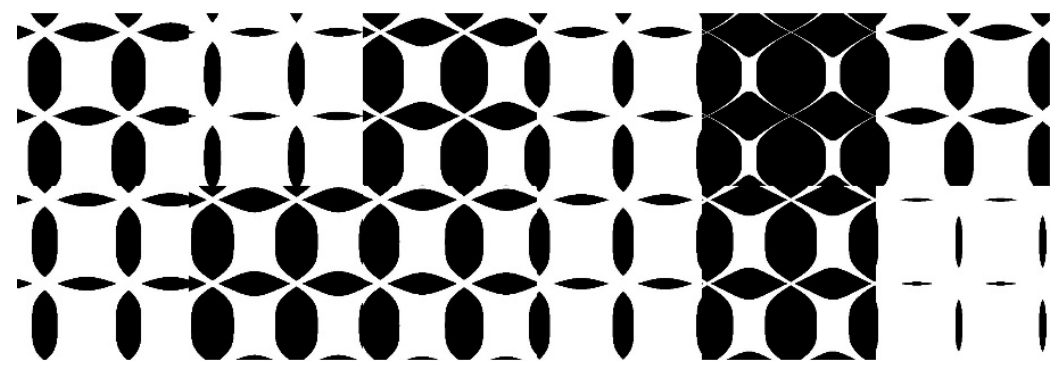

Image 2. The test for raster (screen) shapes for 12 four-bit pixels (hexadecimally: 8c5b19 a67b4e).

Brightness of the pixels, top row (hexa/16) is: $50 \%, 75 \%, 31.25 \%, 68.75 \%, 6.25 \%, 56.25 \%$.

FourHorns screen is applied to the word "ORIGINAL" which is hidden (nestled) as Z graphics: 


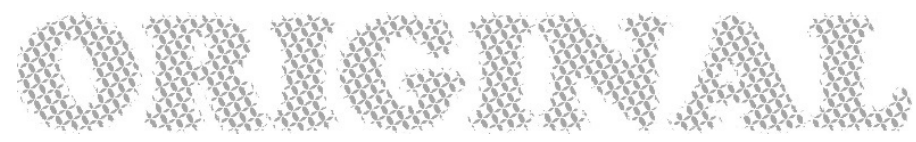

Image 3. Design of hidden information

The word ORIGINAL is in the FourHorns screen which will appear in the NIR spectrum. In the visual position of the letter $\mathrm{N}$ is letter $G$ from the NIR design. Letter $G$ is identical to channel $\mathrm{K}$ after VZ separation. Shown in image 4 are the print channels $\mathrm{C}, \mathrm{M}$, Y from $\mathrm{VZ}$ separation.

The letters BLENDNIR in the design are colored with a random selection of colors (6 to 10) from table 1 . The area around the letters is designed with lighter tones ( 1 to 5 ). For each color the twin has been experimentally determined in order to integrate the $\mathrm{Z}$ image into the visual image.

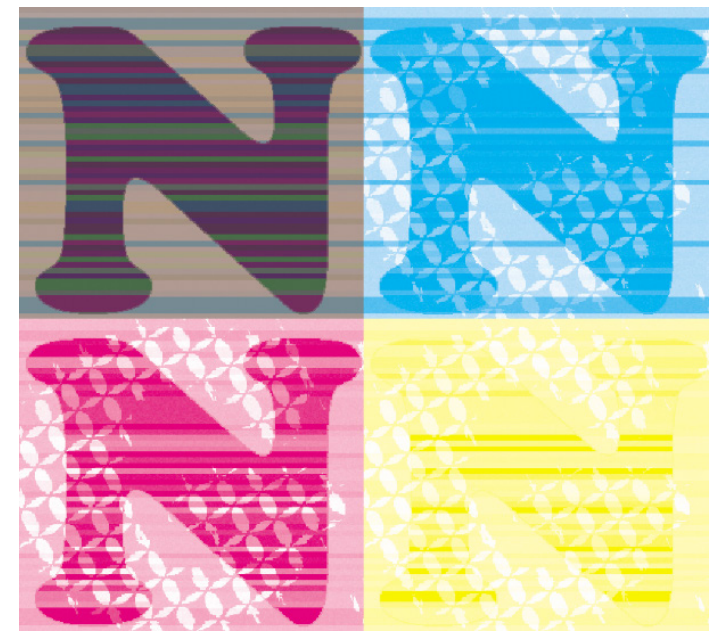

Image 4. Separation according to the VZ procedure of combining two images

\section{Forensic approach to the dual VZ design of information on the drug BLENDNIR}

The photography of the imprint (which carries the dual information) was conducted with the forensic system Projektina [10] in eight positions. The barrier at $570 \mathrm{~nm}$ closed the wavelength of the blue tone so there is no image of the imprint with yellow color (image 5). The manifestation of the magenta colorant is "invisible" at $645 \mathrm{~nm}$. The writing with the cyan colorant is significantly weakened in photography with a blockade above 715 $\mathrm{nm}$. Above $780 \mathrm{~nm}$ only the carbon black colorant, which was camouflaged in the visual image as special safety information, is registered. A disturbance of the initial design for observation with the naked eye occurred already at the first light blockade at $570 \mathrm{~nm}$. The hidden image of the drawing of the portrait of the girl and the letters of the word ORIGINAL start to show. The mark "GF4" is composed of yellow and magenta. This information is pale; it is colorless already at blockades above $700 \mathrm{~nm}$ (animation, image 6).
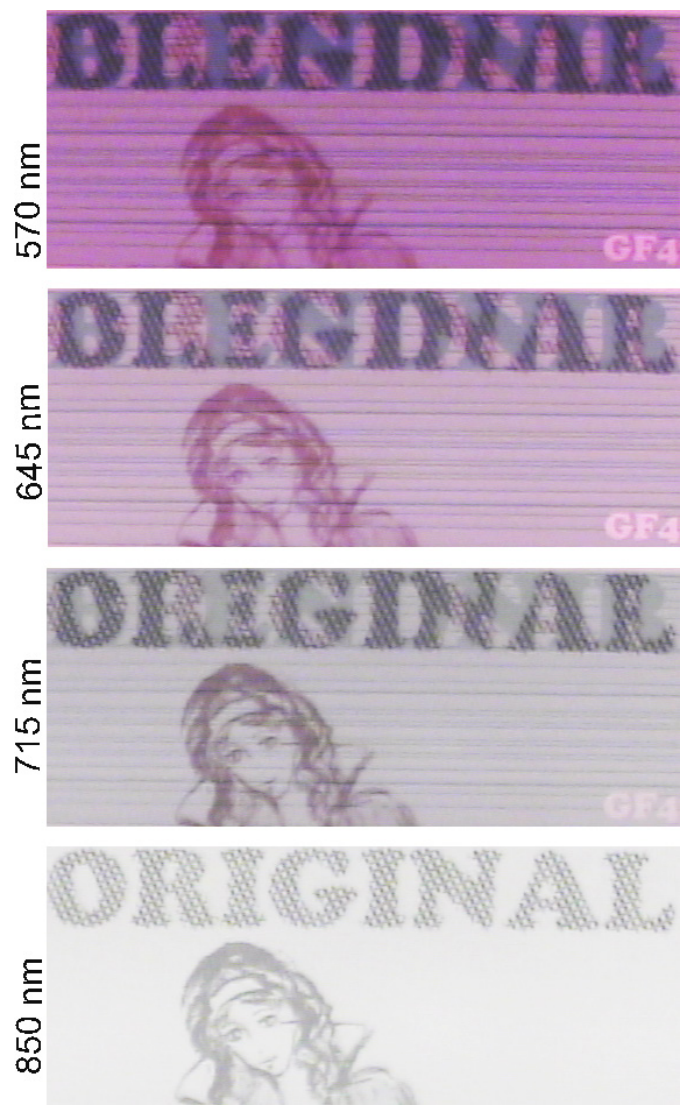

Image 5. Barriers at 570, 645, 715 and 850 nanometers 


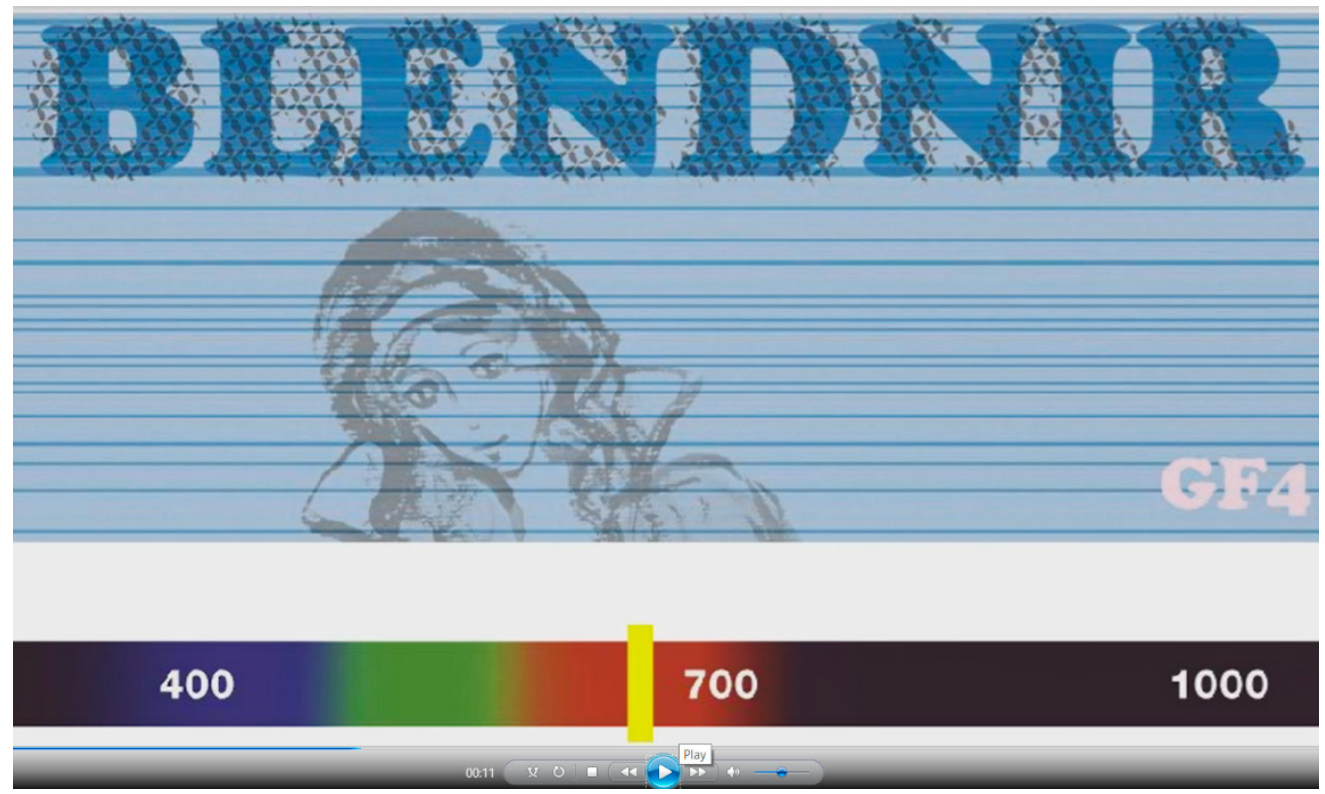

Image 6. The transformation of the BLENDNIR text design.

Through marking the barriers in the range of the visual and NIR spectrum, the changes of the dual design as a forensic method of determining the originality of information on the packaging of the drug BLENDNIR are presented.

Eight barrier photographs were combined in an animation of changes from 400 to 1000 $\mathrm{nm}$. Image 6 shows the animation stopped at ca $650 \mathrm{~nm}$. The video is posted at the address: www.Jana.ziljak.hr/blendnir.mp4

\section{Conclusion}

Graphic design for security print is performed with twins of color and colorants in order to ensure dual design for the visible and nearinfrared spectrum. The same color is realized with two different recipes with different amounts of $\mathrm{C}, \mathrm{M}, \mathrm{Y}, \mathrm{K}$ process colorants. The recipe of colorants have been the basis for any possible proof of packaging authenticity. Design is planed and published together with the animation in continuous change from visual area to the NIR wavelength range of light.

Due to the external conditions of moisture concentration, changes of temperature and the unequal ageing of colorants, there is a decrease in the effect of hiding information in the INFRAREDESIGN procedure. Packaging is affected by climatic conditions, which changes the balance between $\mathrm{C}, \mathrm{M}, \mathrm{Y}, \mathrm{K}$ colors in the printing process. The visual appearance of twin colors could be disrupted. This article suggests a solution to the problem of changes in light absorption properties by introducing a new form of screening. The source code of the new print screen raster, called "four horns", is given. Why is this application important? IRD is a sensitive area in the image hiding process. Our suggestion is for the raster sceern cell form to have a very irregular microstructure where white areas alternate with the edges of the graphic screen element. The structure of the geometry of the screen element is enhanced as an originally designed space of the mathematical definition of the vibrating border of two and more process colorants. The application is demonstrated on drug packaging which is affected by external conditions after long usage. A longer period of use of such packaging could present a problem in the forensic proving of the authenticity of the packaged product. The design of the packaging needs to be enhanced with the information on the light absorption in a wide range of wavelengths - from 400 to 1000 $\mathrm{nm}$. This shows the expanded protection of the IRD design of packaging with multiple content: the individualized raster, the dual range of light, the security check with the animation showing the changes of the graphic solution. 


\section{References}

1. Pap, Klaudio; Žiljak, Ivana; Žiljak-Vujic, Jana; Image Reproduction for Near Infrared Spectrum and the Infraredesign Theory, Journal of Imaging Science and Technology, vol. 54, no. 1, pp. 10502-1-105029(9), DOI: https://doi.org/10.2352/J.ImagingSci. Technol.2010.54.1.010502

2. Jana Žiljak Vujic, Ivana Žiljak Stanimirovic, Olivera Međugorac; HIDDEN INFORMATION IN VISUAL AND INFRARED SPECTRUM, Informatologija 45, 2012., 2, pp.96 - 102, UDK : 655.3.06:7.05:535-1 https://hrcak.srce.hr/file/126351

3. Martina Friščić, Olivera Međugorac, Lidija Tepeš, Denis Jurecic, Invisible information on the transparent polymer food packaging with Infra V/Z technology, TTEM Vol 8/4,/ 2013; P: 1512 -1519, ISSN:1840-1503, e-ISSN 1986-809X

4. Li, C.; Wang, C.; Wang, S.J. A Black Generation Method for Black Ink Hiding Infrared Security Image. // Applied Mechanics and Materials, Trans Tech Publications, Switzerland, Vol. 262 (2013), pp. 9-12. DOI: 10.4028/www.scientific.net/AMM.262.9

5. Zhu Mingzhenga, Chen Zhe, Liu Haoxueb, The Research on Special Printing Effects Based on Gray Component Replacement, Advanced Materials Research Online: 2010-12-06, ISSN: 1662-8985, Vol. 174, pp 251-254, doi:10.4028/www.scientific.net/ AMR.174.251

6. Caiyin Wang, Chao Li, Lijiang Huo Dalian, A Security Printing Method by Black Ink Hiding Infrared Image, Applied Mechanics and Materials Online: 2012-10-26, ISSN: 1662-7482, Vol. 200, pp 730-733, doi:10.4028/www.scientific.net/ AMM.200.730
7. Denis Jurecic, Vilko Žiljak, Lidija Tepeš Golubić, Jana Žiljak Gršić, Spectroscopy of Colorants for Fine Art in Visual and Near Infrared spectrum, Journal of Applied Spectoscopy, Springer 2018, Applied Physics, System Science and Computers II, pp 56.62;

8. Žiljak,V, Pap, K, Žiljak-Stanimirovic, I: DEVELOPMENT OF A PROTOTYPE FOR ZRGB INFRAREDESIGN DEVICE. // Technical Gazette. 18 (2011), 2; p:153-159

9. Ivan Rajkoviæ, Vilko Žiljak; Usage of ZRGB video camera as a detection and protection systemand development of invisible infrared design; Polytechnic \& Design; ZAGREB UNIVERSITY OF APPLIED SCIENCES; Vol. 4, No. 1, 2016. pp: 54 - 59; ISSN 2459-6302; ISSN ;1849-1995 ; DOI: 10.19279/TVZ. PD.2016-4-1-07

10. Projectina Docucenter 4500, high resolution IR Colour Digital Camera, Spectral range $350 \mathrm{~nm}$ $1000 \mathrm{~nm}$. Camera Barrier Filter Module with IR filter values: 780, 830, 850 and $1000 \mathrm{~nm}$. http://www. telectronics.biz/assets/mainmenu/104/editor/PDF_ leaflet_Docucenter_4500.pdf https://web.archive. org/web/20110830234641/http://www.projectina.ch/ cre8.upload/pdfs/UCM\%20LED\%20PIA-7000\%20 2011-e.pdf

11. Jana Žiljak Gršić; Near infrared spectroscopy in print technology; polytechnic \& design Vol. 5, No. 1, 2017. pp:32-36; DOI: 10.19279/TVZ.PD.2017-5-1-05, DOI: 10.19279/TVZ.PD.2017-5-1-05-en

12. Jana Žiljak Gršić, Double QR code with cross color twins for visual and infrared spectrum, Polytechnic \& Design Vol. 6, No. 3, 2018. p:159-165, DOI: 10.19279/TVZ.PD.2018-6-3-14. 